\title{
THE DARK TRIAD AND PERCEPTIONS OF ORGANISATIONAL JUSTICE AMONG TEACHING STAFF IN PRIVATE HIGHER EDUCATION
}

\author{
Katarina Sokići, \\ Sarwar Khawaja ${ }^{2}$, \\ Fayyaz Hussain Qureshi ${ }^{3}$ \\ ${ }^{1}$ Dr., Research Associate, \\ Oxford Business College, \\ 65 George Street, Oxford, \\ United Kingdom \\ orcid.org/0000-0001-7522-1228 \\ ${ }^{2}$ Chairman Business Development, \\ Oxford Business College, \\ 65 George Street, Oxford, \\ United Kingdom \\ ${ }^{3}$ Dr., Director of Research and Quality Assurance, \\ Oxford Business College, \\ 65 George Street, Oxford, \\ United Kingdom \\ orcid.org/0000-0003-1305-9493
}

\begin{abstract}
:
The main purpose of this study was to examine the relationship between The Dark Triad components (Machiavellianism, Narcissism, and Psychopathy), and perceptions of the different organisational justice dimensions (distributive, procedural, and interactional) among teaching staff in private higher education. The sample included 277 participants (106 male, 171 female) aged 23 to 65. Self-report data were collected online using the Short Dark Triad, and The Organisational Justice Perceptions Questionnaire. Results have shown significant gender differences in the perception of organisational justice. Psychopathy was negatively related to the perception of distributive, procedural, and interactional justice only in men. Narcissism uniquely positively predicted distributive, procedural, and interactional justice in women. Machiavellianism showed no significant effects on perceptions of organisational justice dimensions in both men and women, which suggests that Machiavellianism operates similarly across gender regarding organisational justice. The positive effect of narcissism on the perception of procedural and interactional justice was more pronounced when associated with low Machiavellianism, which indicates that Machiavellianism indirectly negatively affects
\end{abstract}

\footnotetext{
i Correspondence: email katarina.sokić@oxfordbusinesscollege.ac.uk, sarwar.khawaja@oxfordbusinesscollege.ac.uk, fayyaz.qureshi@oxfordbusinesscollege.ac.uk
} 
the perception of organisational justice. The results highlight the importance of including dark traits in explaining the perception of organisational justice.

Keywords: Dark Triad, organisational justice, teaching staff, private higher education

\section{Introduction}

Scientific and practical interest in organisational justice and its interaction with employee personal characteristics has grown during the past decades (Kwantes, 2019; Törnroos et al., 2018). The demand for justice is one of the most significant challenges for private and public organisations. The term organisational justice refers to the employee's perception of fairness associated with different cognitive, emotional, and behavioural reactions (Greenberg, 1987). Cropanzano et al. (2007) defined organisational justice as "personal evaluation about the ethical and moral standing of managerial conduct" (p. 35).

Justice in organisational context encompasses three components: the justice of outcomes (distributive justice), the justice of the methods and procedures used in the organisational decision-making process, (procedural justice), and the justice in information transmission (interactional justice) (Cropanzano \& Greenberg, 1997; McDowall \& Fletcher, 2004). All three components are interconnected but arise from different managerial actions (Cropanzano et al., 2007). Organisational justice is one of the major determinants of job satisfaction, job performance, and employees' affective organisational trust commitment. It could help build synergy between organisational goals and employee expectations (Fat et al. 2010; Suifan, 2019). Also, organisational justice significantly influences employees' physical and mental health as well as their subjective well-being (Colquitt et al., 2013). Interaction between individual and organisation is complex and depend on organisational practices, and on the other hand, it depends on individual-level factors (Kwantes \& Bond, 2019). The framework of organisational justice (organisational structure, climate, reward systems, conflict management, etc.) reflect on an individual employee in depending on the employee's personal characteristics such as personality, behaviour, attitudes, values, beliefs, cynicism, work stress, and negative emotion (Colquitt et al., 2006; Grawitch et al., 2006; Kwantes \& Bond, 2019; Pérez-Rodríguez et al., 2019).

Perception of organisational justice and justice, honesty, and equity, in general, differ across individuals (Greenberg, 2001). Individual differences in perception of organisational justice, organisational support, and working environment are influenced by personality traits (neuroticism, extraversion, openness, conscientiousness, agreeableness) (Altuntaş et al., 2021; Elovianio et al., 2003; Shi et al., 2009; Törnroos et al., 2018). Besides normal personality traits, there are also traits, which are socially undesirable, entail a malevolent character, with behaviour tendencies toward antagonistic, self-interested, and often related to anti-social thoughts and behaviour in private life and work environment. 
These traits are in the subclinical range and called dark traits or Dark Triad, are Machiavellianism, narcissism, and psychopathy (Paulhus \& Williams, 2002). Dark traits share some core characteristics: empathic deficit and callousness (Dinić et al., 2020; Jones \& Figueredo, 2013; Furnham et al., 2013). The behaviour of individuals with pronounced dark traits is socially repulsive and undesirable but not necessarily outside the normal range of functioning.

The last two decades, increasing attention has been focused on the study of dark traits, especially in an organisational context related to counterproductive work behaviours, interpersonal conflict in the workplace, and „toxic“ leadership (Baloch et al., 2017; DeShong et al., 2015; Jonason et al., 2012; O’Boyle et al., 2011; Sokić \& Lukač, 2018). However, to the best of our knowledge, the impact of the Dark Triad on the perception of organisational justice has not been examined. Therefore, this paper will examine relationships between dark traits and dimensions of organisational justice among teaching staff in private higher education.

\section{Literature review}

\subsection{The Dark Triad in the organisational framework}

Despite the common features mentioned above, each of the traits encompassed in the Dark Triad construct has some specific characteristics. For example, Machiavellianism involves interpersonal manipulativeness and exploitation, distrust, goal-focused behaviour, cynicism, and an abnormal view of morality (Monagham et al., 2018). Narcissism includes a grandiose sense of self-importance, entitlement, self-enhancement, lacking trust and care for others, dominance, and superiority (Spain et al., 2014; Wright et al., 2013). Psychopathy is characterised by extreme traits such as callousness, lack of remorse, egocentricity, manipulativeness, poor behavioural control, aggression, and an exploitativeness attitude toward others (Crego \& Widiger, 2016; Stanley et al., 2013). Relationships between the Dark Triad and workplace outcomes have received less attention in comparison with normal personality traits. However, in recent times organisational psychologists and human resource departments have shown increased interest in the effect of the dark personality on work behaviour (especially counterproductive), job performance, job attitudes. The meta-analysis by O'Boyle et al. (2012) indicated that all three dark traits were associated with counterproductive workplace behaviour. This type of intentionally undesirable, deviant work behaviour includes physical violence, mobbing, sexual harassment, destruction of the organisation's property, abuse of information, neglect of security regulations, and avoidance of work obligations (Robinson, 2003; Vanden Bos, 2015). Meta-analysis (O'Boyle et al., 2012) also showed that Machiavellianism and psychopathy were associated with low quality of job performance.

Although the relationship between dark traits and job satisfaction is not well explored. However, some studies have shown that Machiavellianism and narcissism have a negative relationship with job satisfaction (see Bruk-Lee et al., 2009), while other 
studies have shown a positive relationship between narcissism and job satisfaction (Abbas \& Kant, 2017). The relationship between psychopathy and job satisfaction is negative (Body, 2011; Foulkers et al., 2014).

A recent study (Čopkova \& Araňošová, 2020) examined the relationship of the Dark Triad and job satisfaction among helping professionals (pedagogical, healthcare, rescue, and social workers) and measured nine aspects of job satisfaction: pay, promotion, supervision, benefits, rewards, conditions, co-workers, nature of work, and communication. The result of this study indicated that dark traits were unrelated to job satisfaction elements associated with financial and non-financial remuneration (pay, benefits, and rewards) and that Machiavellianism and psychopathy were negatively related to overall job satisfaction. Machiavellianism had negative relationships with satisfaction with co-workers, nature of work, and communication. Psychopathy had negative relationships with satisfaction with supervision, co-workers, the nature of work, and communication. In contrast, narcissism had a positive relationship with satisfaction with promotion and a negative relationship with satisfaction with co-workers and communication.

Balock et al. (2017) tested mediating role of perceptions of organisational politics in the relationship between the Dark Triad and counterproductive work behaviour and the moderating role of political skills in the relationship between the Dark Triad and the perceptions of organisational politics. Organisational politics was defined as "individual or group behaviour that is informal, ostensibly parochial, typically divisive, and above all in a technical sense, illegitimate-sanctioned neither by formal authority, accepted ideology, nor certified expertise" (Ferris et al., 2002).

Political skills were defined as the "ability to understand others at work effectively and to use such knowledge to influence others to act in ways that enhance one's personal and/or organisational objectives" (Treadway et al., 2013). Accordingly, it is reasonable to expect that individuals with high political skills know how to use these skills to achieve their selfish goals (Ferris et al., 2005). It has been shown that perceptions of organisational politics partially mediate the link between Dark Triad and counterproductive work behaviour. Therefore, the presence of political skills among the Dark Triad may increase counterproductive work behaviour. Also, results showed that political skills positively moderate the effect on the relationship between Machiavellianism, narcissism, and perceptions of organisational politics, but the moderation effect was not found regarding the link between psychopathy and perceptions of organisational politics (Balock et al., 2017).

The above studies have shown that the components of the Dark Triad are differently related to organisational outcomes. Although the relationship between the Dark Triad and perception of organisational justice has not been examined, the theoretical background and hypotheses of the study are explained below. 


\subsection{Effects the Dark Triad on perception of organisational justice}

The perception of organisational injustice and unequal treatment obstructs organisational goals. Employees who perceive a low level of organisational justice develop negative emotions such as angry, resistance, and disappointment (Folger, 1993). Organisational justice in all its dimensions (distributive, procedural and interactional) negatively correlated to perceived stress and negative emotions (anger, frustration, anxiety, depression)) (Pérez-Rodríguez, 2019). Furthermore, this study has shown the mediating role of negative emotions in the relationship between organisational justice perceptions and stress. Together with previous findings found in a study by Barski et al. (2011), these findings indicate that negative emotions significantly affect organisational fairness judgments in two ways: as predictors perception of organisational justice or perceived inequality.

A positive relationship between perceived organisational injustice and anger and deviant workplace behaviour was also found in a study by Khattak et al. (2018). This study has shown that perception of distributive and procedural injustice predicts deviant work behaviours towards organisations and that perception of interactional injustice predict deviant behaviours towards individuals. Moderation analysis indicated that neuroticism and agreeableness moderate the relationship between anger and deviant workplace behaviour; the relationship between anger and deviant behaviours was stronger and more positive on a high level of neuroticism and a low level of agreeableness (Khattak et al., 2018). A negative relationship on the bivariate level was found between the perception of organisational justice and psychopathy, while Machiavellianism and narcissism were unrelated to the perception of organisational justice (Cohen \& Liu, 2021). Also, this study showed that Machiavellianism significantly positively predicted interpersonal and organisational counterproductive work behaviour, psychopathy positively predicted interpersonal counterproductive work behaviour. At the same time, narcissism was not a significant predictor of counterproductive work behaviour. Similar findings were found in a study conducted by Geraghty (2019), which showed that dark traits in a situation of perceived organisational injustice lead to counterproductive work behaviours.

\subsection{Present study and hypothesis}

The main purpose of this study is to contribute a better understanding of the relations between the Dark Triad components (Machiavellianism, narcissism, and psychopathy) and different dimensions of organisational justice (distributive, procedural, and interactional). Also, given the mixed results in the Dark Triad as well as perceptions of organisational justice across genders (Jepsen \& Rodwell, 2010), we will examine whether the relationships between the Dark Triad and dimensions of organisational justice differ across gender. To better understand individual factors which affect perceptions of organisational justice including dark traits we need to know more about the role of dark personality in perceptions of organisational justice. The Dark Triad components are related to aversive, socially deviant, and malevolent behaviour including aggression, 
retaliation, exploitation, and destruction. Also, all three Dark Triad components are characterized by emotional deficiencies, low empathy, an external orientation to achieve one's goals, and a limited ability to communicate one's emotions towards others (Jonason et al., 2012). These characteristics can play a significant role in the perception of organisational justice and elicit negative reactions with harmful outcomes for individuals and organisations as a whole. Based on the above literature review, we proposed that Machiavellianism would be negatively related to the perception of organisational justice, narcissism would be positively related to the perception of organisational justice, and psychopathy would be negatively related to the perception of organisational justice. Given the antagonism inherent in Machiavellianism and psychopathy, we expect negatively affect these dark traits to the relationship between narcissism and the perception of organisational justice.

As we did not have any a priori hypotheses regarding the gender differences in the Dark Triad - perception of organisational justice relationship, analyses of gender differences were considered exploratory.

\section{Methods}

\subsection{Sample and procedures}

The study population consisted of the teaching staff in private higher education institutions in Croatia. All of the participants have a university degree, $57 \%$ of them have a doctoral degree, and $25 \%$ have a master's degree. Our sample consists of professors $(34 \%)$, senior lecturers $(27 \%)$, lecturers $(26 \%)$, and assistants (13\%). Questionnaire data for 28 participants were excluded from analyses due to missing data, and the final sample comprised 277 participants (106 male, 171 female), aged from 23 to $65($ Mage $=37$, SDage $=$ 10.06). Questionnaires were anonymous and participants give consent before taking part in the study. Data were collected online from the summer and autumn of 2021. All aspects of the study were approved by the Ethics Committee from the Department of Psychology, Faculty of Humanities and Social Sciences, University of Zagreb. Participants did not receive a fee to participate in the survey. The size of the study sample was above the minimum of 250 recommended for correlational studies (Schönbrodt \& Perugini, 2013).

\subsection{Instruments}

\subsubsection{Perceptions of organisational justice}

The Organisational Justice Perceptions Questionnaire (OJPQ; Jakopec \& Sušanj, 2014) was used as a measure of three dimensions of organisational justice: distributive, procedural, and interactional. This instrument contains 15 items scored on a five-point scale (from $1=$ strongly disagree to $5=$ strongly agree). Each dimension of organisation justice contains five items. Examples of items are: „The organisation rewards me fairly for the effort I put into my job"(distributive justice), "The organisation very clearly explains its decisions and provides additional information when I request it" (procedural justice), and „My organisation makes it clear that I am hardworking“. The lowest possible 
score on the scales is 5 and the highest possible score is 25 . Higher scores indicate more positive perceptions of each of the dimensions of organisational justice. Cronbach's alpha coefficients for distributive, procedural, and interactional justice scales were $.97, .95$, and .96. In order to test dimensionality of the OJPQ a maximum-likelihood confirmatory factor analysis (CFA) in AMOS Version 26 was conducted. The model is acceptable when Comparative Fit Index (CFI) $>0.90$, Tucker-Lewis Index (TLI) $>0.90$, Root Mean Square Error of Approximation (RMSEA) $<0.08$, and Standardized Root Mean Squared Residual $(S R M R)<0.08$ (Brown, 2006). In this study results of CFA showed good fit for the OJPQ model: $\chi^{2}(68)=238.12 ; p<.001 ; \mathrm{CFI}=0.94$; TLI $=0.93$, RMSEA $=0.06$, and SRMR $=0.06$, with three high correlated components of organisational justice.

\subsubsection{The Dark Triad}

The Short Dark Triad (SD3; Jones \& Paulhus, 2014) was used to measure three dark traits: Machiavellianism, narcissism, and psychopathy. The instrument consists of 27 items scored on a 5 -point Likert scale ranging from $1=$ strongly disagree to $5=$ strongly agree, with 9 items devoted to each of the three scales. Examples of items are: "Make sure your plans benefit yourself, not others" (Machiavellianism), "I insist on getting the respect I deserve." (narcissism), and „People who mess with me always regret it “(psychopathy). Cronbach's alpha coefficients for Machiavellianism, narcissism and psychopathy scales were $.81, .73$, and .75 . In order to test dimensionality of the SD3 maximum-likelihood confirmatory factor analysis (CFA) in AMOS Version 26 was conducted. Results of CFA showed good fit for the SD3 model: $\chi^{2}(46)=170.12 ; p<.001$; CFI $=0.92$; TLI $=0.93$, RMSEA $=0.06$, and SRMR $=0.06$.

\subsection{Data analysis}

In order to test the dimensionality of used scales, confirmatory factor analysis in AMOS Version 26 was conducted. Descriptive and correlational analyses of the variables of the study were performed. Descriptive and correlational analysis of all studies variables were performed in order to test reliabilities for study variables. To compare men and women in the mean level of dark traits and perceived organisational justice and examine possible gender differences, a one-way ANOVA was used. To quantify bivariate correlations between all using scales, zero-order correlations were calculated. In order to determine whether gender moderates the relationship between Dark Triad traits and organisational justice dimensions, three hierarchical linear regression models were performed with gender and age entered at Step 1, Dark Triad traits entered at Step 2, and the three Gender $x$ Dark Triad traits entered at Step 3. There was no significant increase in $R^{2}\left(\Delta R^{2}\right)$ on the third step of regression analyses, showing that gender $x$ Dark Triad interactions were not found. To predict organisational justice dimensions based on Dark Triad, six hierarchical multiple regression analyses were performed. The age was included as a control variable in the 1st step, and scores on three Dark Triad scales were entered in the 2nd step. 


\section{Results}

\subsection{Descriptive statistic, gender differences and bivariate correlations}

Reliabilities for study variables, descriptive statistics, and gender differences are reported in Table 1. All used scales demonstrated an adequate range and internal psychometric characteristics. Alpha reliabilities for the SD3 scales were .81, .73, and .75 for Machiavellianism, narcissism, and psychopathy, and for the OJPQ alpha reliabilities were $.97, .95$, and .96 for distributive justice, procedural justice and interactional justice, respectively. Skewness and kurtosis for all scales were within the recommended values for normal distribution (between -2 to +2) (Gravetter \& Wallnau, 2014). One-way ANOVA was used to assess gender differences for all measures. Independent samples tests showed that men scoring significantly higher on the SD3 total score $(d=0.73)$, Machiavellianism $(d=0.49)$, narcissism $(d=0.40)$, and on psychopathy $(d=0.74)$. There were no gender differences on organisational justice dimensions.

Table 1: Reliabilities and descriptive statistics for OJPQ and SD3 scales in men $(n=106)$ and woman $(n=171)$

\begin{tabular}{|l|c|c|c|c|c|c|c|c|}
\hline & Men & Women & \multicolumn{3}{|c|}{} \\
\cline { 2 - 9 } & $M(S D)$ & $M(S D)$ & $F(1,276)$ & $d$ & Range & $\alpha$ & Sk & $\mathrm{Ku}$ \\
\hline SD3 total & $73.27(12.58)$ & $64.52(11.70)$ & $38.49^{* *}$ & 0.73 & $33-118$ & .85 & 0.35 & 1.25 \\
\hline Machiavellianism & $26.76(6.18)$ & $23.82(5.78)$ & $17.04^{* *}$ & 0.49 & $11-45$ & .81 & 0.41 & 0.29 \\
\hline Narcissism & $25.98(4.90)$ & $23.91(5.46)$ & $12.59^{* *}$ & 0.40 & $9-42$ & .73 & -0.27 & 0.87 \\
\hline Psychopathy & $20.52(5.49)$ & $16.80(4.48)$ & $40.41^{* *}$ & 0.74 & $9-39$ & .75 & 0.66 & 0.61 \\
\hline OJPQ total & $49.93(13.20)$ & $47.57(16.01)$ & 1.88 & 0.16 & $15-75$ & .97 & -0.32 & -0.62 \\
\hline Distributive justice & $16.58(5.10)$ & $15.52(5.75)$ & 2.46 & 0.20 & $5-25$ & .97 & -0.19 & -0.88 \\
\hline Procedural justice & $16.41(4.64)$ & $15.53(5.46)$ & 2.23 & 0.17 & $5-25$ & .95 & -0.35 & -0.55 \\
\hline Interactional justice & $16.93(4.38)$ & $16.52(5.73)$ & 0.64 & 0.08 & $5-25$ & .96 & -0.43 & -0.48 \\
\hline Note Or & & &
\end{tabular}

Note: OJPQ = The Organisational Justice Perceptions Questionnaire, SD3 = The Short Dark Triad.

Maximal range of response for all scale is $1-5 . d=$ Cohen's $d$ index. Effect sizes around 0.2 are considered small, 0.5 medium, and 0.8 large (Cohen, 1988).

$\alpha=$ Cronbach's. $\alpha$. Sk - skewness, $\mathrm{Ku}-$ kurtosis.

${ }^{*} p<.01,{ }^{* *} p<.001$ (two-tailed tests).

Bivariate correlations between study variables are displayed in Table 2. Intercorrelations between the Dark Triad traits were small $(r=.18)$ to moderate $(r=.53)$. Machiavellianism was unrelated with narcissism in men $(r=.18, p>.05)$, but in women relationship between these two dark traits was significantly positive $(r=.27, p<.001)$. Correlations between Machiavellianism and psychopathy were moderate in both men and women, as well as the correlation between psychopathy and narcissism in men $(r=.34, p<.001)$. Intercorrelations between dimensions of organisation justice were high $(r>.80)$.

Results have shown that narcissism is significantly positively related to distributive, procedural, and interactional justice only in women. Psychopathy negatively related with distributive and procedural justice only in men, while 
Machiavellianism was unrelated to dimensions of organisational justice in both men and women.

Table 2: Bivariate correlations of SD3 and OJPQ scales $\left(n_{\text {men }}=106\right.$ and $\left.n_{\text {women }}=171\right)$

\begin{tabular}{|l|c|c|c|c|c|c|c|c|}
\hline & $\mathbf{1 .}$ & $\mathbf{2 .}$ & $\mathbf{3 .}$ & $\mathbf{4}$ & $\mathbf{5}$ & $\mathbf{6 .}$ & $\mathbf{7 .}$ & $\mathbf{8}$. \\
\hline 1. SD3 total & - & $.80^{* * *}$ & $.63^{* * *}$ & $.83^{* * *}$ & .13 & -.17 & -.12 & -.08 \\
\hline 2. Machiavellianism & $.82^{* * *}$ & - & .18 & $.53^{* * *}$ & -.13 & -.13 & -.12 & -.11 \\
\hline 3. Narcissism & $.67^{* * *}$ & $.27^{* * *}$ & - & $.34^{* * *}$ & .07 & .04 & .03 & .12 \\
\hline 4. Psychopathy & $.73^{* * *}$ & $.53^{* * *}$ & $.18^{*}$ & - & $-.22^{*}$ & $-.27^{* *}$ & $-.18^{*}$ & -.16 \\
\hline 5. OJPQ total & .11 & .02 & $.28^{* * *}$ & -.08 & - & $.93^{* * *}$ & $.93^{* * *}$ & $.94^{* * *}$ \\
\hline 6. Distributive justice & .08 & -.02 & $.28^{* * *}$ & -.11 & $.93^{* * *}$ & - & $.79^{* * *}$ & $.81^{* * *}$ \\
\hline 7. Procedural justice & .14 & .07 & $.24^{* *}$ & -.03 & $.95^{* * *}$ & $.81^{* * *}$ & - & $.83^{* * *}$ \\
\hline 8. Interactional justice & .09 & .00 & $.28^{* * *}$ & -.11 & $.95^{* * *}$ & $.82^{* * *}$ & $.88^{* * *}$ & - \\
\hline
\end{tabular}

Note: Correlations above the diagonal are for men, and below for women.

OJPQ = The Organisational Justice Perceptions Questionnaire, SD3 = The Short Dark Triad.

${ }^{*} p<.05,{ }^{* *} p<.01,{ }^{* * *} p<.001$ (two-tailed tests).

\subsection{Predicting organisational justice from the Dark Triad domain scores}

To examine the distinctive contributions of the Dark Triad components in predicting organisational justice dimensions, we performed three regression analyses for each gender with the Dark Triad components (Machiavellianism, narcissism, and psychopathy) included together as predictors in Step 2. Age was included as the control variable in all regressions in Step 1. Criteria variables were three dimensions of organisational justice (distributive, procedural, and interactional) (Table 3). Results of multiple regression analysis have shown that the Dark Triad components together explained significant amounts of variance in distributive (10\%), and interactional justice (7\%) in men, and significant amounts of variance in all three dimensions of organisational justice in women (9\% in distributive and interactional justice, and 5\% in procedural justice). For both men and women, age negatively predicted perceptions of interactional justice ( $B=-.22$ and $-.25, p<.01)$. In women sample age negatively predicted distributive and procedural justice $(B=-.23$ and $-.24, p<.01)$. The results showed that, in the second step, narcissism uniquely positively predicted distributive $(B=.30, p<.001)$, procedural $(B=.24, p<.01)$, and interactional justice $(\beta=.30, p<.001)$ only in women. Psychopathy uniquely negatively predicted distributive $(B=-.34, p<.001)$, procedural $(B=-.21, p<$ $.05)$, and interactional justice $(B=-.23, p<.05)$ only in men. The scores on Machiavellianism were unrelated to organisational justice dimensions in both men and women. 
Table 3: Hierarchical linear regression analysis: prediction of distributive, procedural and interactional justice based on Machiavellianism, narcissism and psychopathy

\begin{tabular}{|c|c|c|c|c|c|c|}
\hline & \multicolumn{3}{|c|}{ Men $(n=106)$} & \multicolumn{3}{|c|}{ Woman $(n=171)$} \\
\hline & DJ & $\mathrm{PJ}$ & IJ & DJ & PJ & IJ \\
\hline & $\beta$ & $\beta$ & $\beta$ & $\beta$ & $\beta$ & $\beta$ \\
\hline Age & -.10 & -.16 & $-.22^{*}$ & $-.23^{* *}$ & $-.24^{* *}$ & $-.25^{* *}$ \\
\hline$R^{2}$ & .01 & .03 & $.05^{*}$ & $.05^{* *}$ & $.06^{* *}$ & $.06^{* *}$ \\
\hline Age & -.14 & $-.20^{*}$ & $-.25^{*}$ & $-.22^{* *}$ & $-.23^{* *}$ & $-.24^{* *}$ \\
\hline Machiavellianism & -.00 & -.07 & -.07 & -.11 & -.03 & -.09 \\
\hline Narcissism & .13 & .08 & .17 & $.30^{* * *}$ & $.24^{* *}$ & $.30^{* * *}$ \\
\hline Psychopathy & $-.34^{* *}$ & $-.21^{*}$ & $-.23^{*}$ & -.11 & -.06 & -.11 \\
\hline$\Delta R^{2}$ & $.10^{*}$ & .05 & $.07^{*}$ & $.09^{* *}$ & $.05^{* *}$ & $.09^{* *}$ \\
\hline Total $R^{2}$ & $.11^{*}$ & .08 & $.12^{*}$ & $.14^{* *}$ & $.11^{* *}$ & $.15^{* *}$ \\
\hline \multicolumn{7}{|c|}{$\begin{array}{l}\text { Note: } \mathrm{DJ}=\text { Distributive justice, } \mathrm{PJ}=\text { Procedural justice, } \mathrm{IJ}=\text { Interactional justice. } \\
\beta=\text { Standardized regression coefficients. } R=\text { multiple regression coefficients, } \\
R^{2}=\text { coefficient of determination, } \Delta R^{2}=\text { the change in } R^{2} \text { relative to the previous step in the regression. } \\
{ }^{*} p<.05,{ }^{* *} p<.01,{ }^{* * *} p<.001 \text { (two-tailed tests). }\end{array}$} \\
\hline
\end{tabular}

\subsection{Moderation analyses}

Three hierarchical regression analysis was conducted to test the moderation effect of Machiavellianism on the relationship between the other two Dark Triad components (narcissism and Psychopathy) and organisational justice (distributive justice, procedural and interactional). Gender and age were included as control variables in the first step of all regression analyses. Results are presented in Table 4 . The independent variables (Machiavellianism, narcissism, and psychopathy) were standardized. The three standardized variables were entered in the second step of the regression analysis and the products of the three independent variables were entered in the third step, with three dimensions of organisational justice as the dependent variables. Results showed that the effect of gender was significant for all dimensions of organisational justice, and that effect of age was insignificant except in interactional justice $(\beta=-12, p<.05)$.

Table 4: Regression analysis for the moderation (dependent variables: distributive justice, procedural justice, and interactional justice)

\begin{tabular}{|c|c|c|c|c|c|c|c|c|c|}
\hline \multirow{3}{*}{ Variable } & \multicolumn{3}{|c|}{ Model 1} & \multicolumn{3}{|c|}{ Model 2} & \multicolumn{3}{|c|}{ Model 3} \\
\hline & DJ & PJ & IJ & DJ & PJ & IJ & DJ & PJ & IJ \\
\hline & $\beta$ & $\beta$ & $\beta$ & $\beta$ & $\beta$ & $\beta$ & $\beta$ & $\beta$ & $\beta$ \\
\hline \multicolumn{10}{|l|}{ Controls } \\
\hline Age & -.08 & -.07 & -.03 & $-.12^{*}$ & -.09 & -.06 & -.11 & -.08 & -.05 \\
\hline Gender & $-.19^{* *}$ & $-.21^{* *}$ & $-.23^{* * *}$ & $-.19^{* *}$ & $-.20^{* *}$ & $-.23^{* * *}$ & $-.18^{* *}$ & $-.18^{* *}$ & $-.21^{* *}$ \\
\hline \multicolumn{10}{|l|}{ Main effects } \\
\hline Machiavellianism & - & - & - & -.05 & -.03 & -.07 & -.05 & -.03 & -.09 \\
\hline Narcissism & - & - & - & $.24^{* * *}$ & $.19^{* *}$ & $.26^{* * *}$ & $.25^{* * *}$ & $.21^{* *}$ & $.28^{* * *}$ \\
\hline Psychopathy & - & - & - & $-.23^{* *}$ & $-.15^{*}$ & $-.18^{*}$ & $-.22^{* *}$ & -14 & $20^{*}$ \\
\hline \multicolumn{10}{|l|}{ Moderation } \\
\hline $\begin{array}{l}\text { Machiavellianism x } \\
\text { narcissism }\end{array}$ & & & & - & - & - & -.09 & $-.19^{*}$ & $-.19^{*}$ \\
\hline $\begin{array}{l}\text { Machiavellianism x } \\
\text { psychopathy }\end{array}$ & & & & - & - & - & -.01 & .00 & .10 \\
\hline
\end{tabular}




\begin{tabular}{|l|c|c|c|c|c|c|c|c|c|}
\hline $\begin{array}{l}\text { Narcissism } x \\
\text { psychopathy }\end{array}$ & & & & - & - & - & .06 & .11 & .06 \\
\hline$R^{2}$ & $.04^{* *}$ & $.05^{* *}$ & $.06^{* *}$ & $.14^{* * *}$ & $.10^{* *}$ & $.14^{* * *}$ & .14 & .11 & .16 \\
\hline$\Delta R^{2}$ & $.04^{* *}$ & $.05^{* *}$ & $.06^{* *}$ & $.09^{* * *}$ & $.05^{* *}$ & $.09^{* * *}$ & .01 & .02 & .02 \\
\hline $\begin{array}{l}\text { Note: DJ = Distributive justice, PJ = Procedural justice, IJ = Interactional justice. } \\
{ }^{*} p<.05,{ }^{* *} p<.01,{ }^{* * *} p<.001\end{array}$
\end{tabular}

The effect of Machiavellianism on the relationship between narcissism and procedural justice, as well as on the relationship between narcissism and interactional justice was significant. As we can see in Figure 1 and Figure 2, on the low level of Machiavellianism, narcissism showed a positive effect on the perception of both procedural and interactional justice. These results indicated that high Machiavellianism negatively affects the positive perception of procedural and interactional justice.

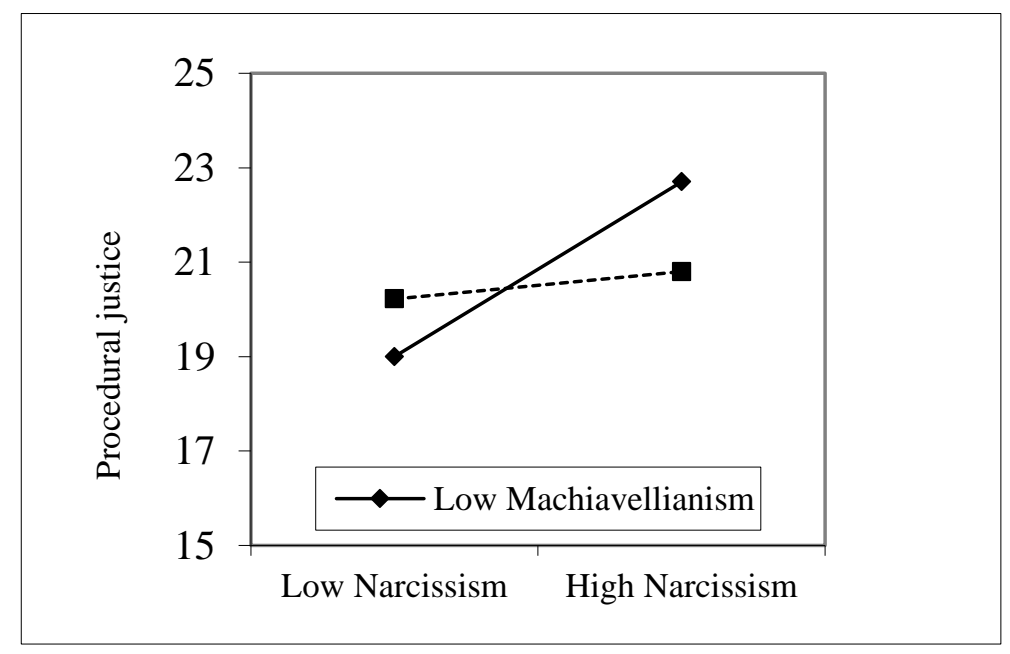

Figure 1: The moderation effect of Machiavellianism on relationship between narcissism and procedural justice

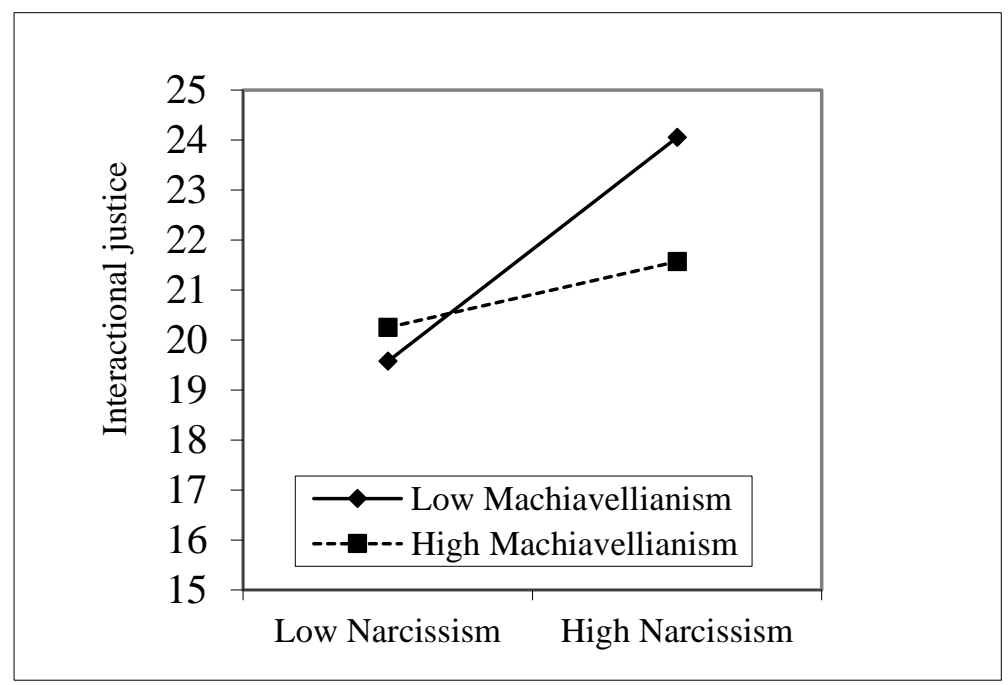

Figure 2: The moderation effect of Machiavellianism on relationship between narcissism and interactional justice 


\section{Discussion}

This study examined the relationship between The Dark Triad components (Machiavellianism, narcissism, and psychopathy), and perceptions of the different organisational justice dimensions (distributive, procedural, and interactional) among teaching staff in private higher education as well as the gender differences between these variables.

In general, the results of the study suggested that the Dark Triad traits are an important predictor of the perception of organisational justice. Overall, the Dark Traits predicted from 5 to $10 \%$ of the variance in perceptions of a specific dimension of organisational justice in men, and from 5 to $9 \%$ of the variance of this criterion in women. Among the dark traits, psychopathy emerged as the best predictor of negative perceptions of organisational justice in men but not in women. The lack of positive emotions and morality, self-centeredness, and tendency to exploit others, are some of the core characteristics of psychopathy (Glenn et al., 2010; Blair et al., 2006), which may influence perceived organisational injustice among persons with psychopathy traits. The absence of the expected negative link between psychopathy and organisational justice in the sample of women may be explained by significantly lower scores on psychopathy in women sample in line with a previous study (Dinić \& Wertag, 2018, Međedović et al., 2018). Narcissism has shown a positive association with all dimensions of organisational justice which is in line with the adaptive role of this dark trait and its connection with extraversion and openness (e.g., Paulhus \& Williams, 2002).

Contrary to prediction, Machiavellianism was unrelated to perceptions of organisational justice but it has been shown that Machiavellianism indirectly negatively affected perceptions of organisational justice by reducing the positive relationship between narcissism and procedural and interactional justice. This finding is consistent with the assumption that manipulativeness, distrust, selfishness, and a strategiccalculating orientation are some of the key features of Machiavellianism traits (Jones \& Figueredo, 2013; Monaghan et al., 2018).

On the other hand, moderation effects Machiavellianism on the relationship between narcissism and perception of organisational justice indicate that role of narcissism in an organisational context depends on the presence of the other two dark lines. We can assume that in relation to some other organisational outcomes such as loyalty to the organisation both psychopathy and Machiavellianism have a negative impact. Besides, our results showed that the Dark Triad explained similar amounts of variance in dimensions of organisational justice in both men and women may suggest that dark traits have an important role in both men in women in the perception of organisational justice. Overall, our results point to the central negative role of psychopathy in the relationship between dark traits and perceptions of organisational justice. The results also showed that gender has no moderated role in this relationship, although it should be noted that the relationship between dark traits and perception of organisational justice depends on gender. The adaptive role of narcissism in women and 
the maladaptive role of psychopathy in men in relation to the perception of organisational justice should be examined in other professions as well as in the future conduct new studies among teaching and non-teaching staff in private higher education. There are several limitations to this study that need to be acknowledged. First, the participants consisted of a homogenous sample of teaching staff rather than employees in other organisations. For these reasons, further research is needed to evaluate the generalizability of findings to other samples. Additionally, further studies may use other measures of perceptions of organisational justice, as well as other measures of dark traits.

\section{Conclusion and practical implications}

In this study, we demonstrated for the first time the link between The Dark Triad traits and perceptions of organisational justice among teaching staff in private higher education. The results were consistent with the proposed direct relationship of psychopathy in men and narcissism in women with all three dimensions of organisational justice. The proposed direct relationship between Machiavellianism with perceptions of organisational justice was not found. Results indicates that Machiavellianism indirectly affects the perception of organisational justice because reduces the positive relation between narcissism and this organisational outcome.

\section{Funding Statement}

This research did not receive any specific grant from funding agencies in the public, commercial, or not-for-profit sectors.

\section{Declaration of Conflicting Interests}

The authors declare no potential conflicts of interest with respect to the research, authorship, and/or publication of this article.

\footnotetext{
About the Authors

Dr. Katarina Sokić, PhD in Psychology, MSc in Civil Law, Research Associate, Oxford Business College, 65 George Street, Oxford, United Kingdom.

Sarwar Khawaja, MBA, LLM, Chairman Business Development, Oxford Business College, 65 George Street, Oxford, United Kingdom.

Dr. Fayyaz Hussain Qureshi, BA, (Economics and Journalism); BSc (Botany, Zoology and Chemistry); MA (English Literature); MBA (Marketing); MBA (Finance); MSc (Internet Technologies); Doctorate in Marketing; PGD (Organisations Knowledge); Director of Research and Quality Assurance; Oxford Business College, 65 George Street, Oxford, United Kingdom.
} 


\section{References}

Abbas, S. S., \& Kant, V. (2017). Gender as moderator of narcissism and job satisfaction: study on comparative assessment of banking and FMCG sectors in Delhi NCR. International Journal of Research in Business and Management, 4(1), 7-15. http://dx.doi.org/10.22259/ijrbsm.0401002

Altuntaş, S., Harmanci Seren, A. K., Alaçam, B., \& Baykal, Ü. (2021). The relationship between nurses' personality traits and their perceptions of management by values, organisational justice, and turnover intention. Perspectives in Psychiatric Care, 1-9. https://doi.org/doi:10.1111/ppc.12873

Baloch, M. A., Meng, F., Xu, Z., Cepeda-Carrion, I.; Danish, B., \& Muhammad W. (2017). Dark Triad, Perceptions of Organisational Politics and Counterproductive Work Behaviors: The Moderating Effect of Political Skills. Frontiers in Psychology, 8, 1972, https://doi.org/10.3389/fpsyg.2017.01972

Barsky, A., Kaplan, S. A., \& Beal, D. J. (2011). Just feelings? The role of affect in the formation of organisational fairness judgments. Journal of Management, 37(1), 248279. https://doi.org/10.1177/0149206310376325

Blair, R. J., Peschardt, K. S., Budhani, S., Mitchell, D. G., Pine, \& D. S. (2006). The development of psychopathy. Journal of Child Psychology and Psychiatry, 47, 262-76. https://doi.org/doi:10.1111/j.1469-7610.2006.01596.x

Boddy, C. R. (2011). Corporate Psychopaths and Job Satisfaction. In Corporate Psychopaths (pp. 93-98). Palgrave Macmillan: London.

Bruk-Lee, V., Khoury, H., Nixon, A., Goh, A., \& Spector, P. (2009). Replicating and extending past personality/job satisfaction meta-analyses. Human Performance, 22, 156-189. https://doi.org/doi:10.1080/08959280902743709

Colquitt, J. A., Scott, B. A., Rodell, J. B., Long, D. M., Zapata, C. P., Conlon, D. E., \& Wesson, M. J. (2013). Justice at the millennium, a decade later: A meta-analytic test of social exchange and affect-based perspectives. The Journal of Applied Psychology, 98(2), 199-236. https://doi.org/10.1037/a0031757

Colquitt, J. A., Scott, B. A., Judge, T. A., \& Shaw, J. C. (2006). Justice and personality: Using integrative theories to derive moderators of justice effects. Organisational Behavior and Human Decision Processes, 100(1), 110-127. https://doi.org/10.1016/j.obhdp.2005.09.001

Crego, C., \& Widiger, T. A. (2016). Cleckley's psychopaths: revisited. Journal of Abnormal Psychology, 125, 75-87. http://dx.doi:10.1037/abn0000130

Cropanzano, R., Bowen, D. E., \& Gilliland, S. W. (2007). The management of organisational justice. Academy of Management Perspectives, 21(4), 34-48. https://doi.org/10.5465/amp.2007.27895338

Cropanzano, R., \& Greenberg, J. (1997). Progress in organisational justice: Tunneling through the maze. In: C.L. Cooper i I.T. Robertson (Ed.), International review of industrial and organisational psychology (pp. 317-372). New York: John Wiley \& Sons. 
Čopková, R., \& Araňošová, A. (2020). The Relationship of Dark Triad and Job Satisfaction among Helping Professionals. Človek a spoločnost' [Individual and Society], 23(3), 1833. http://doi.org/10.31577/cas.2020.03.574

DeShong, H. L., Grant, D. M., \& Mullins-Sweatt, S. N. (2015). Comparing models of counterproductive workplace behaviors: The Five-Factor Model and the Dark Triad. Personality and Individual Differences, 74, 55-60. https://doi.org/10.1016/j.paid.2014.10.001

Dinić, B. M., Wertag, \& A. (2018). Effects of Dark Triad and HEXACO traits on reactive/proactive aggression: Exploring the gender differences. Personality and Individual Differences, 123, 44-49. https://doi.org/doi:10.1016/j.paid.2017.11.003

Dinić, B. M., Wertag, A., Tomašević, A., \& Sokolovska, V. (2020). Centrality and redundancy of the Dark Tetrad traits. Personality and Individual Differences, 155, 109621. https://doi.org/10.1016/j.paid.2019.109621

Elovainio, M., Kivimäki, M., Vahtera, J., Virtanen, M., \& Keltikangas-Järvinen, L. (2003). Personality as a moderator in the relations between perceptions of organisational justice and sickness absence. Journal of Vocational Behavior, 63(3), 379-395. https://doi.org/10.1016/S0001-8791(02)00058-1

Fatt, C. K., Wong Sek Khin, E., \& Heng, T. N. (2010). The Impact of Organisational Justice on Employee's Job Satisfaction: The Malaysian Companies Perspectives. American Journal of Economics and Business Administration, 2(1), 56-63. https://doi.org/10.3844/ajebasp.2010.56.63

Ferris, G. R., Adams, G., Kolodinsky, R. W., Hochwarter, W. A., \& Ammeter, A. P. (2002). "Perceptions of organisational politics: theory and research directions", in The Many Faces Multi Level Issues, eds F. J. Yammarino and F. Dansereau (Emerald Group Publishing Limited), 179-254. https://doi.org/10.1016/S1475-9144(02)01034$\underline{2}$

Ferris, G. R., Treadway, D. C., Kolodinsky, R. W., Hochwarter, W. A., Kacmar, C. J., Douglas, C., et al. (2005). Development and validation of the political skill inventory. Journal of Management, 31, 126-152. https://doi.org/10.1177/0149206304271386

Folger, R. (1993). Reactions to mistreatment at work. Social Psychology in Organisations: Advances in Theory and Research, 161-183.

Foulkes, L., McCrory, E. J., Neumann, C. S., \& Viding, E. (2014). Inverted social reward: Associations between psychopathic traits and self-report and experimental measures of social reward. PloS one, 9(8). https://doi.org/10.1371/journal.pone.0106000

Furnham, A., Richards, S. R., \& Paulhus, D. L. (2013). The Dark Triad of personality: A 10 year review. Social and Personality Psychology Compass, 7(3), 199-216. https://doi.org/10.1111/spc3.12018

Geraghty, S. M. (2019). Examining perceived organisational injustice as a moderator in the relationship of dark tetrad personality traits to counterproductive work behavior. Master's thesis. Southern Illinois University, Carbondale, Illinois. 
Gravetter, F. i Wallnau, L. (2014). Essentials of statistics for the behavioral sciences (8th edition). Belmont, CA: Wadsworth.

Grawitch, M. J., Gottschalk, M., \& Munz, D. C. (2006). The path to a healthy workplace: A critical review linking healthy workplace practices, employee well-being, and organisational improvements. Consulting Psychology Journal: Practice and Research, 58(3), 129-147. https://doi.org/10.1037/1065-9293.58.3.129

Greenberg, J. (1987). A taxonomy of organisational justice theories. Academy of Management Review, 12(1), 9-22.

Greenberg, J. (2001). Setting the justice agenda: Seven unanswered questions about "what, why, and how". Journal of Vocational Behavior, 58(2), 210-219. https://doi.org/10.1006/jvbe.2001.1792

Jakopec, A., \& Sušanj, Z. (2014). Verifying the Dimensionality of Justice Construct in Organisational Context [Provjera dimenzionalnosti konstrukta pravednosti $\mathrm{u}$ organizacijskom kontekstu]. Psihologijske teme, 23(2), 305-325. https://hrcak.srce.hr/125095

Jepsen, D. M., \& Rodwell, J. (2012). Female Perceptions of Organisational Justice. Gender, Work and Organisation, 19(6),723-740. https://doi.org/10.1111/j.1468$\underline{0432.2010 .00538 . x}$

Jonason, P. K., Slomski, S., \& Partyka, J. (2012). The Dark Triad at work: how toxic employees get their way. Personality and Individual Differences, 52(3), 449-453. https://doi.org/10.1016/j.paid.2011.11.008

Jones, D. N., \& Figueredo, A. J. (2013). The core of darkness: Uncovering the heart of the Dark Triad. European Journal of Personality, 27(6), 521-531. https://doi.org/10.1002/per.1893

Jones, D. N., \& Paulhus, D. L. (2014). Introducing the Short Dark Triad (SD3) a brief measure of dark personality traits. Assessment, 21, 28-41. https://doi.org/10.1177/1073191113514105

Khattak, M. N., Khan, M. B., Fatima, T., \& Shah, S. Z. A. (2019). The underlying mechanism between perceived organisational injustice and deviant workplace behaviors: Moderating role of personality traits. Asia Pacific Management Review, 24(3), 201-211. https://doi.org/10.1016/j.apmrv.2018.05.001

Kwantes, C. T., Bond, \& M. H. (2019). Organisational justice and autonomy as moderators of the relationship between social and organisational cynicism. Personality and Individual Differences, 151, S0191886919302764-. https://doi.org/10.1016/j.paid.2019.04.046

McDowall, A., \& Fletcher, C. (2004). Employee development: An organisational justice $\begin{array}{lllll}\text { perspective. Personnel } & \text { Review, } & \text { 8-29. }\end{array}$ http://dx.doi.org/10.1108/00483480410510606

Međedović, J., Wertag, A., \& Sokić, K. (2018). Can Psychopathic Traits be Adaptive? Sex Differences in Relations between Psychopathy and Emotional Distress. Psihologijske teme, 27 (3), 481-497. https://doi.org/10.31820/pt.27.3.7 
Monaghan, C., Bizumic, B., \& Sellbom, M. (2018). Nomological network of twodimensional Machiavellianism. Personality and Individual Differences, 130, 161-173. http://dx.doi.org/10.1016/j.paid.2018.03.047

O'Boyle, E. H., Forsyth, D. R., Banks, G. C., and McDaniel, M. A. (2012). A metaanalysis of the Dark Triad and work behavior: a social exchange perspective. Journal of Applied Psychology, 97, 557-579. http://dx.doi.org/10.1037/a0025679

Paulhus, D. L., \& Williams, K. (2002). The Dark Triad of personality: Narcissism, Machiavellianism, and Psychopathy. Journal of Research in Personality, 36, 556-568. https://doi.org/10.1016/S0092-6566(02)00505-6

Pérez-Rodríguez, V., Topa, G., \& Beléndez, M. (2019). Organisational justice and work stress: The mediating role of negative, but not positive, emotions. Personality and Individual Differences, 151, 109392. https://doi.org/10.1016/j.paid.2019.04.047

Robbins, S. P. (2003). Essentials of Organisational Behaviour. New Jersey: Prentice Hall.

Schönbrodt, F. D., \& Perugini, M. (2013). At what sample size do correlations stabilize? Journal of Research in Personality, 47, 609-612. https://doi.org/10.1016/j.jrp.2013.05.009.

Shi, J., Lin, H., Wang, L., \& Wang, M. (2009). Linking the big five personality constructs to organisational justice. Social Behavior and Personality, 37(2), 209-222. https://doi.org/10.2224/sbp.2009.37.2.209

Sokić, K., \& Lukač, M. (2018). Successful psychopathy: reality or myth? FIP - Financije i pravo, $6(1), 7-28$.

Spain, S. M., Harms, P. i LeBreton, J. M. (2014). The dark side of personality at work. Journal of Organisational Behavior, 35(S1), S41-S60. https://doi.org/10.1002/job.1894

Stanley, J. H., Wygant, D. B., \& Sellbom, M. (2013). Elaborating on the construct validity of the triarchic psychopathy measure in a criminal offender sample. Journal of Personality Assessment, 95, 343-350. http://dx.doi.org/10.1080/00223891.2012.735302

Suifan, T. S. (2019). The Effect of Organisational Justice on Employees' Affective Commitment the Mediating Role of Job Satisfaction. Modern Applied Science, 13 (2), 42 - 53. https://doi.org/10.5539/mas.v13n2p42

Törnroos, M., Elovainio, M., Hintsa, T., Hintsanen, M., Pulkki-Råback, L., Jokela, M., Lehtimäki, T., Raitakari, O. T., \& Keltikangas-Järvinen, L. (2019). Personality traits and perceptions of organisational justice. International Journal of Psychology, 54, (3), 414-422. https://doi.org/10.1002/ijop.12472

Treadway, D. C., Witt, L. A., Stoner, J., Jansen Perry, S., \& Shaughnessy, B. A. (2013). Political skill as a moderator of the relationship between subordinate perceptions of interactional justice and supervisor ratings of interpersonal facilitation. American Journal of Business. 28, 233-251. https://doi.org/10.1108/AJB-08-2013-0058 VandenBos, G. R. (2015). APA dictionary of psychology. Washington: DC: American Psychological Association 
Wright A. G. C., Pincus A. L., Thomas K. M., Hopwood C. J., Markon K. E., \& Krueger R. F. (2013). Conceptions of narcissism and the DSM-5 pathological personality traits. Assessment, 20(3), 339-352. https://doi.org/10.1177/1073191113486692 will be applied to their work. Under the terms of this license, no permission is required from the author(s) or publisher for members of the community to copy, distribute, transmit or adapt the article content, providing a proper, prominent and unambiguous attribution to the authors in a manner that makes clear that the materials are being reused under permission of a Creative Commons License. Views, opinions and conclusions expressed in this research article are views, opinions and conclusions of the author(s). Open Access Publishing Group and European Journal of Education Studies shall not be responsible or answerable for any loss, damage or liability caused in relation to/arising out of conflicts of interest, copyright violations and inappropriate or inaccurate use of any kind content related or integrated into the research work. All the published works are meeting the Open Access Publishing requirements and can be freely accessed, shared, modified, distributed and used in educational, commercial and non-commercial purposes under a Creative Commons Attribution 4.0 International License (CC BY 4.0). 